\title{
Nanosized silica-titanium oxide as a potential adsorbent for C.I. Acid Yellow 219 dye removal from textile baths and wastewaters
}

\author{
Małgorzata Wiśniewska ${ }^{1} \cdot$ Monika Wawrzkiewicz ${ }^{2}$ Ewelina Polska-Adach ${ }^{2} \cdot$ Gracja Fijałkowska $^{1}$. Olena Goncharuk ${ }^{3}$
}

Received: 23 December 2017 / Accepted: 5 February 2018 / Published online: 5 March 2018

(c) The Author(s) 2018. This article is an open access publication

\begin{abstract}
The mixed $\mathrm{SiO}_{2}-\mathrm{TiO}_{2}$ oxide obtained by the pyrogenic method with the silica:titanium percentage ratio equal to 80:20 (ST20) was used as a potential adsorbent for the removal of hazardous azo dye C.I. Acid Yellow 219 (AY219) from aqueous solutions. Based on the values of determination coefficients $\left(r^{2}\right)$, it can be stated that the Freundlich $\left(r^{2}=0.929\right)$ model fitted the experimental data better than the Langmuir $\left(r^{2}=0.920\right)$ and Tempkin $\left(r^{2}=0.848\right)$ ones. In the system containing $20 \mathrm{mg} / \mathrm{L}$ AY219, the amount of dye adsorbed $\left(q_{t}\right)$ by ST20 was equal to $9.7 \mathrm{mg} / \mathrm{g}$ and the time necessary to reach equilibrium was $120 \mathrm{~min}$. The sorption of AY219 on ST20 may be described by the pseudo-second-order model $\left(r^{2}=0.999\right)$ as the adsorption capacity was calculated as $9.69 \mathrm{mg} / \mathrm{g}$. The amount of AY219 adsorbed decreased with the increasing concentration of additives such as anionic and non-ionic (Triton X-100) surfactants. In the presence of cationic surfactant, the reverse dependence was observed. Anionic dye additions influence the structure of electrical double layer formed on the surface of mixed oxide particles. The presence of negative charges in adsorbed AY219 molecules results in increase of the solid surface charge density with simultaneous decrease of the zeta potential of ST20 particles. The addition of surfactants with different ionic character causes formation of complexes whose presence at the mixed oxide-liquid interface influences considerably both the solid surface charge density and the zeta potential of ST20 particles dispersed in aqueous solution.
\end{abstract}

Keywords Nanosized mixed oxide $\cdot$ Silica-titanium oxide $\cdot$ Acid yellow $\cdot$ Removal $\cdot$ Sorption $\cdot$ Electrokinetic properties

\section{Introduction}

Acid dyes are usually sodium salts of sulphonic acid or carboxylic acid. They contain azo, anthraquinone, triarylmethane, or nitro groups as the main chromophore (Mielicki 1991). Acid dyes containing azo groups make up 60-70\% of all produced dyes. They are soluble in water and alcohol and are almost completely dissociated in dyeing baths creating coloured anions and sodium cations. They are

Małgorzata Wiśniewska

wisniewska@hektor.umcs.lublin.pl

1 Faculty of Chemistry, Maria Curie-Sklodowska University, Department of Radiochemistry and Colloid Chemistry, $\mathrm{M}$. Curie-Sklodowska Sq. 3, 20-031 Lublin, Poland

2 Faculty of Chemistry, Maria Curie Sklodowska University, Department of Inorganic Chemistry, M. Curie-Sklodowska Sq. 2, 20-031 Lublin, Poland

3 O. O. Chuiko Institute of Surface Chemistry, National Academy of Science of Ukraine, 17 General Naumov Str, Kiev 03164, Ukraine mainly intended for dyeing of wool, silk, and nylon in the strongly and weakly acidic media in the presence of mineral or organic acids like sulphuric, acetic, or formic as well as in neutral baths. Moreover, they are applied as colorants for plastics, paper, leather, paints and lacquers, printing inks, etc. The US Food and Drug Administration (FDA) certified over 3000 tons of azo dyes for the use in foods, cosmetics, and pharmaceutical products (Chung 2016).

Textile industry consumes over 7000 different compounds including dyes, surface active agents, and electrolytes (Hessel et al. 2007). It was reported that due to inefficiencies of the industrial dyeing operations, 280,000 tons of various dyes per year worldwide are discharged in wastewaters (Jin et al. 2007). From 10 to $20 \%$ of acid dyes in a non-fixed form can be released to textile effluents (Hessel et al. 2007). Azo dyes are degraded under anaerobic conditions to toxic aromatic amines in the receiving medium (Robinson et al. 2001). These dyes inhibit the tyrosinase enzyme which leads to inhibition of melanin synthesis and results in hypopigmentation (Harshad et al. 2015). A higher incidence of bladder cancer was observed in workers exposed to azo dyes 
(Chung 2016). For this reason, they pose a serious threat not only to fauna and flora but first of all to human's health. Dyestuffs removal from textile wastewaters is still a major environmental challenge. Adsorption methods are considered to be highly effective in the industrial effluents treatment technologies. Currently, the most important adsorbents used for this purpose are: activated carbons (Deryło-Marczewska et al. 2010; Bazan-Woźniak et al. 2017, 2018) and carbonaceous sorbents (Nowicki et al. 2016), anion exchange resins (Wawrzkiewicz et al. 2017c), hybrid materials (Wawrzkiewicz et al. 2017a), low-cost substances (Janoš and Šmidová 2005), and agroindustry wastes (Garg et al. 2004). The search for not only cheap but also selective adsorbents with a significant sorption capacity is a serious challenge for scientists. Nanosized mixed oxides have been successfully used for the removal of hazardous dyes from model aqueous solutions and textile wastewaters (Wawrzkiewicz et al. 2015, 2017b). Taking into consideration the morphological and microstructural properties of the nanosized oxides as well as mechanical strength and non-toxicity in many cases, these sorbents are becoming increasingly popular from year to year (Rasalingam et al. 2013; Pal et al. 2016; Ciesielczyk et al. 2017; Tanzifi et al. 2018).

This study aims at the removal of disazo textile dye C.I. Acid Yellow 219 from aqueous solutions using mixed silica and titanium oxide. Due to the fact that this dye is applied for wool and polyamide colouring as well as the lack of literature on its removal from textile effluents, it seems reasonable to investigate the possibility of its adsorption. Kinetic and equilibrium sorption parameters were calculated. The influence of different types of surface active agents on the dye adsorption on nanosized oxide was taken into account. Another task of the paper was to investigate the suspension electrokinetic properties making the surface charge density and electrophoretic mobility measurements. Such studies are essential for determination of colloidal system stability which can be influenced, for example, by the presence of macromolecular compounds. They find a wide usage not only as components of plastics (Klepka 2002; Klepka et al. 2009) and also as the effective modifiers of solid particle stability.

\section{Materials and methods}

\section{Adsorbent and adsorbate characteristics}

Mixed $\mathrm{SiO}_{2}-\mathrm{TiO}_{2}$ oxide (pilot plant at the Institute of Surface Chemistry, Kalush, Ukraine) with the silica: titanium percentage ratio 80:20 was used as the adsorbent. It was designated as ST20. The adsorbent was characterized by the following textural parameters: the BET specific surface area $84 \mathrm{~m}^{2} / \mathrm{g}$, the micropore area $8.84 \mathrm{~m}^{2} / \mathrm{g}$, the average pore diameter $12 \mathrm{~nm}$ (mesopores), the total pore volume $0.255 \mathrm{~cm}^{3} / \mathrm{g}$, and the micropore volume $0.003 \mathrm{~cm}^{3} / \mathrm{g}$. They were determined using low-temperature nitrogen adsorption-desorption isotherms method (ASAP 2405 porosimeter, Micromeritics). Mixed $\mathrm{SiO}_{2}-\mathrm{TiO}_{2}$ oxide was obtained applying the pyrogenic synthesis method by co-burning silicon and titanium tetrachlorides in a hydrogen-oxygen flame at a temperature of $1100-1400{ }^{\circ} \mathrm{C}$. The structure of the synthesized mixed oxide depends on many factors, namely the ratio of the initial components, the flame temperature, and the flow velocity. During the synthesis, the TiOTi and SiOSi bonds were mainly formed. Nevertheless, the TiOSi bonds are also present on the surface of mixed oxide (Gun'ko et al. 2007, 2017). The titanium phase in ST20 consists of a major portion of anatase with a minor contribution of amorphous oxide distributed in the silica matrix (Gun'ko et al. 2007). The surface content of titanium in ST20 determined from Auger electron spectra was 24.4\% (Gorbik et al. 2007).

The disazo acid dye, namely C.I. Acid Yellow 219 (AY219), widely applied in the textile industry during dyeing and printing operations was used as an adsorbate. It was purchased from Boruta-Zachem (Poland). Its characteristics are presented in Fig. 1.

Surface active agents used in the experiments such as sodium dodecyl sulphate (SDS), hexadecyltrimethylammonium bromide (CTAB) and 4-(1,1,3,3-tetramethylbutyl)phenyl-polyethylene glycol (Triton X-100) of laboratory grade were ordered from Sigma-Aldrich (Germany) company. The most important properties of the above-mentioned surfactants are also mentioned in Fig. 1.

\section{Adsorption equilibrium and kinetic studies}

The equilibrium and kinetic studies in the AY219-ST20 systems were carried out using the batch method. The experiments were performed in conical flasks at room temperature using a laboratory shaker (Elphin 358S) with the constant speed and amplitude (180 cpm, 8 amplitude). $0.02 \mathrm{~g}$ of ST20 was mixed with $20 \mathrm{~mL}$ of AY219 solution of the known concentration from 5 to $240 \mathrm{~min}$ (kinetic studies) or $24 \mathrm{~h}$ (equilibrium studies). Then, ST20 was separated by the filtration using filter paper. The AY219 concentration in the aqueous phase was determined spectrophotometrically using a UV/Vis spectrophotometer Cary 60 (Agilent) at the maximum absorbance-wavelength $(387 \mathrm{~nm})$. The adsorbed amount of AY219 on ST20 was calculated at equilibrium $\left(q_{\mathrm{e}}\right)$ and at time $\mathrm{t}\left(q_{t}\right)$ using the following equations:

$$
\begin{aligned}
& q_{\mathrm{e}}=\frac{\left(C_{0}-C_{\mathrm{e}}\right)}{m} V, \\
& q_{t}=\frac{\left(C_{0}-C_{t}\right)}{m} V,
\end{aligned}
$$




\section{C.I. Acid Yellow 219 \\ Molecular \\ Formula: $\mathrm{C}_{20} \mathrm{H}_{17} \mathrm{~N}_{4} \mathrm{NaO}_{5} \mathrm{~S}$ \\ Molecular Weight: $448.43 \mathrm{~g} / \mathrm{mol}$}

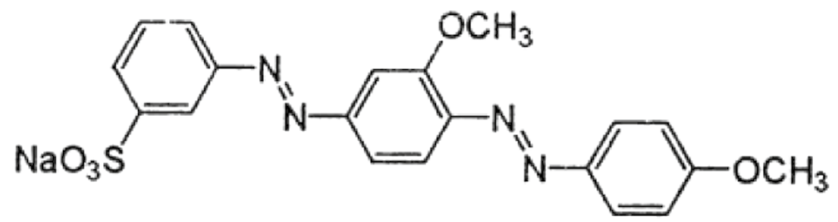

\section{SDS}

Molecular Formula: $\mathrm{C}_{12} \mathrm{H}_{25} \mathrm{NaO}_{4} \mathrm{~S}$

Molecular Weight: $288.4 \mathrm{~g} / \mathrm{mol}$

$\mathrm{CMC}^{*}$ : 6-8 mM

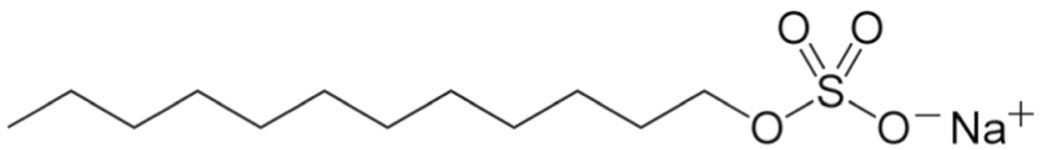

\section{CTAB}

Molecular Formula: $\mathrm{C}_{19} \mathrm{H}_{42} \mathrm{BrN}$ Molecular Weight: $364.5 \mathrm{~g} / \mathrm{mol}$

CMC: $0.92-1.0 \mathrm{mM}$

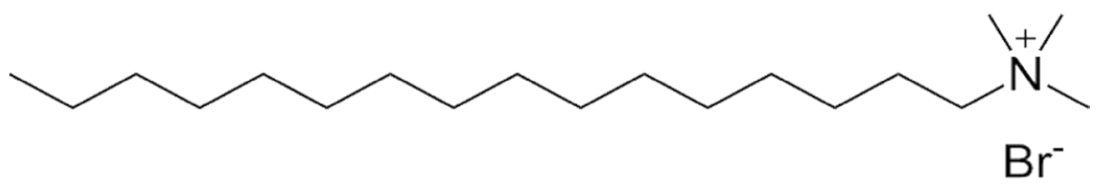

\section{Triton X-100 \\ Molecular Formula: \\ $\mathrm{C}_{14} \mathrm{H}_{22} \mathrm{O}\left(\mathrm{C}_{2} \mathrm{H}_{4} \mathrm{O}\right)_{n}(\mathrm{n}=9-10)$ \\ Molecular Weight: $647 \mathrm{~g} / \mathrm{mol}$ \\ CMC: 0.22-0.24 mM}<smiles>CC(C)Oc1ccc(C2(C)CC(C)(C)C2)cc1</smiles>

$n=9-10$

${ }^{*} \mathrm{CMC}=$ Critical Micelle Concentration

Fig. 1 Physicochemical characteristics of the dye and surfactants

where: $C_{0}, C_{\mathrm{e}}$, and $C_{t}(\mathrm{mg} / \mathrm{L})$ are the concentrations of AY219 in the solution before adsorption, at equilibrium, and at sorption time $t$, respectively, $V(\mathrm{~L})$ is the volume of the dye solution, and $m(\mathrm{~g})$ is the mass of ST20.

To establish the influence of additives such as anionic, cationic, and non-ionic surfactants on AY219 adsorption on ST20, the dye solutions of the initial concentration $20 \mathrm{mg} / \mathrm{L}$ were prepared in the presence of $0.1,0.25$, and $0.5 \mathrm{~g} / \mathrm{L}$ of each of the mentioned surfactants. The phase contact time, ST20 mass, and volume of dye solution were equal to $15 \mathrm{~min}, 0.02 \mathrm{~g}$, and $20 \mathrm{~mL}$, respectively.

\section{Potentiometric titration}

Potentiometric titrations of the examined systems were performed using a specialized set composed of the following parts: thermostat RE 204 (Lauda), glass and calomel electrode (Backman Instruments), pHmeter PHM 240 (Radiometer), automatic microburette Dosimat 765 (Metrohm), and computer with the "titr_v3" program developed by Janusz (1994a). To prepare the aqueous suspension, $0.2 \mathrm{~g}$ of the solid was introduced to $50 \mathrm{~mL}$ of appropriate solution. The following solutions containing ST20 were titrated with
$\mathrm{NaOH}$ (concentration $0.1 \mathrm{~mol} / \mathrm{L}$ ); water (reference solution); dye aqueous solutions of the concentrations 10,20, $30 \mathrm{mg} / \mathrm{L}$; dye aqueous solution (concentrations $20 \mathrm{mg} / \mathrm{L}$ ) with the surfactants-SDS, CTAB, Triton X-100 (concentrations 0.1 and $0.5 \mathrm{~g} / \mathrm{L}$ ). The experiments were performed in the $\mathrm{pH}$ range $3-10$.

The comparison of the titration reference curve with that of suspension (containing mixed oxide) leads to the determination of the solid surface charge density $\sigma_{0}\left(\mu \mathrm{C} / \mathrm{cm}^{2}\right)$. For this purpose, there was used the following equation:

$\sigma_{0}=\frac{\Delta V c_{\mathrm{b}} F}{m S}$,

where: $c_{\mathrm{b}}(\mathrm{mol} / \mathrm{L})$ is the base $(\mathrm{NaOH})$ concentration, $F(\mathrm{C} /$ $\mathrm{mol})$ is the Faraday constant, $m(\mathrm{~g})$ is the solid mass in the suspension, $S\left(\mathrm{~m}^{2} / \mathrm{g}\right)$ is the specific surface area of the solid, and $\Delta \mathrm{V}(\mathrm{L})$ is the difference in the volume of base which must be added to bring the $\mathrm{pH}$ of suspension and reference solution to the specified value.

The potentiometric titration method allows also determination of $\mathrm{pH}_{\mathrm{pzc}}$ value of the examined system (pzc point of zero charge) as a point of the intersection of reference and suspension curves. 


\section{Electrophoretic mobility measurements}

Electrophoretic mobility $U_{\mathrm{e}}\left(\mathrm{cm}^{2} / \mathrm{Vs}\right)$ measurements were made using a zetameter Zetasizer Nano-ZS (Malvern Instruments) equipped with a universal dip cell. The experiments were performed for the same systems as potentiometric titrations. The samples were prepared by the addition of $0.015 \mathrm{~g}$ of the mixed oxide to $100 \mathrm{~mL}$ of the appropriate solution. After 3-min sonification, the obtained suspension was divided into seven parts. In each of them, the appropriate solution $\mathrm{pH}$ value was adjusted (with the accuracy of 0.1 ), namely: $3,4,5,6,7,9$, and 10 .

The Doppler laser electrophoresis technique was applied for measurement of electrophoretic mobility of solid particles. The zeta potential $\zeta(\mathrm{mV})$ was calculated with the special computer program coupled with zetameter using the Henry equation (Hunter 1988):

$U_{\mathrm{e}}=\frac{2 \varepsilon_{0} \varepsilon \zeta}{3 \eta} f(\kappa a)$

where: $\varepsilon$ is the dielectric constant, $\varepsilon_{0}(\mathrm{~F} / \mathrm{m})$ is the electric permeability of vacuum, $\eta(\mathrm{Pa} \cdot \mathrm{s})$ is the viscosity, and $f(\kappa a)$ is the Henry function.

These experiments enable also determination of $\mathrm{pH}_{\text {iep }}$ value of the examined system (iep-isoelectric point) at which the zeta potential of solid particle is equal to zero.

\section{Results and discussion}

\section{Equilibrium and kinetic studies}

The establishment of dependence between the adsorbed amount of AY219 by ST20 and the equilibrium concentration in the solution is a very important task as the shape of isotherm provides useful information about adsorption mechanism (Foo and Hameed 2010; Weber and Morris 1963).

The experimental equilibrium sorption data presented in Fig. 2a were fitted using the most popular isotherm models proposed by the following:

- Langmuir (1918)

$$
\frac{C_{\mathrm{e}}}{q_{\mathrm{e}}}=\frac{1}{Q_{0} b}+\frac{C_{\mathrm{e}}}{Q_{0}}
$$

- Freundlich (1906)

$$
\log q_{\mathrm{e}}=\log k_{\mathrm{F}}+\frac{1}{n} \log C_{\mathrm{e}}
$$
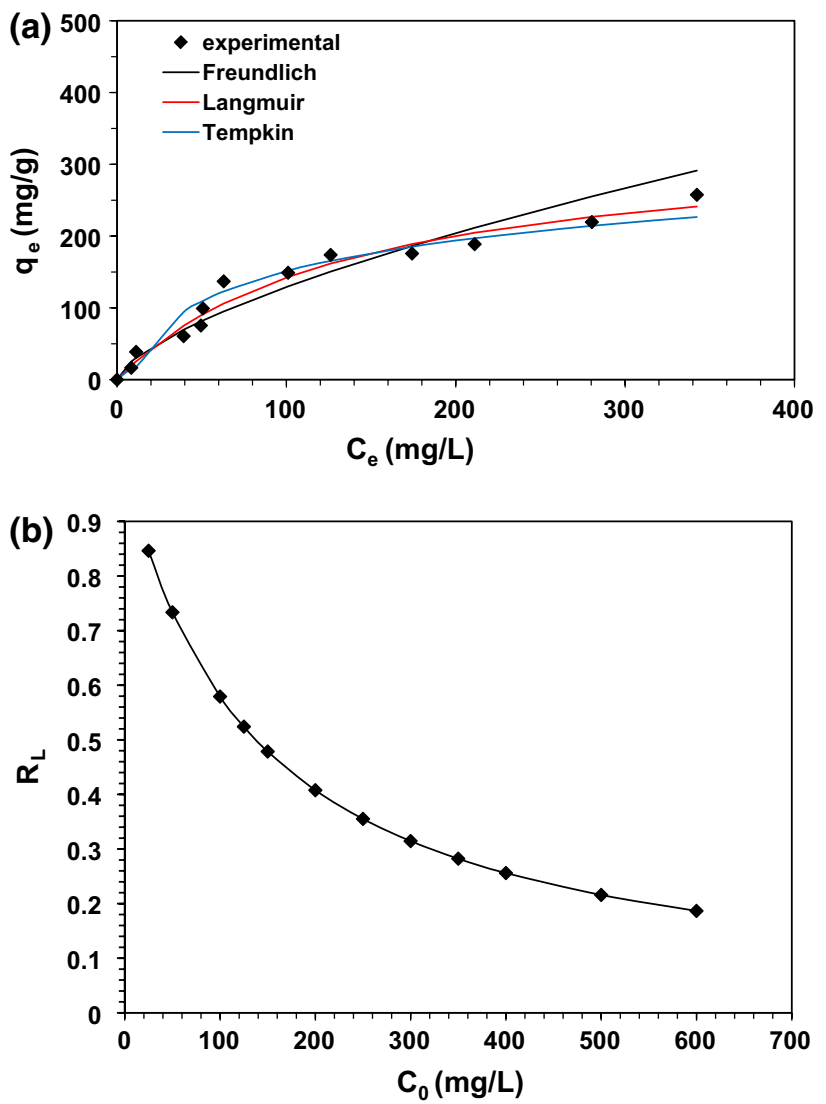

Fig. 2 Fitting of the isotherm models to the experimental equilibrium data (a) and plot of the separation factor vs initial dye concentration (b) in the AY219-ST20 system

- Tempkin (Tempkin and Pyzhev 1940)

$$
q_{\mathrm{e}}=\left(\frac{R T}{b_{T}}\right) \ln A+\left(\frac{R T}{b_{T}}\right) \ln C_{\mathrm{e}},
$$

where: $q_{\mathrm{e}}(\mathrm{mg} / \mathrm{g})$ is the amount of AY219 adsorbed per unit mass of ST20, $C_{\mathrm{e}}(\mathrm{mg} / \mathrm{L})$ is the equilibrium concentration of solution, $Q_{0}(\mathrm{mg} / \mathrm{g})$ is the monolayer adsorption capacity, $b(\mathrm{~L} / \mathrm{mg})$ is the Langmuir constant (related to the free energy of adsorption), $k_{\mathrm{F}}(\mathrm{mg} / \mathrm{g}$ ) and $1 / n$ are the Freundlich constants connected with adsorption capacity of adsorbent and the surface heterogeneity, respectively, $R(8.314 \mathrm{~J} /$ mol K) is the gas constant, $T(\mathrm{~K})$ is the temperature, and $A$ $(\mathrm{L} / \mathrm{g})$ and $b_{T}(\mathrm{~J} / \mathrm{mol})$ are the Tempkin constants.

The adsorption parameters were calculated from the slopes and intercepts of the corresponding plots $C_{\mathrm{e}} / q_{\mathrm{e}}$ versus $C_{\mathrm{e}}, \log q_{\mathrm{e}}$ versus $\log C_{\mathrm{e}}$, and $q_{\mathrm{e}}$ versus $\ln C_{\mathrm{e}}$.

According to the Langmuir model, the adsorbate form on the surface of the adsorbent is the so-called monolayer molecules interacting with the adsorption sites and not interacting (or very weakly interacting) with each other. The adsorption centers are characterized by constant adsorption 
energy. Synthesized silica-titanium oxide ST20 is characterized by a relatively high adsorption capacity $\left(Q_{0}\right)$ equal to $338.4 \mathrm{mg} / \mathrm{g}$ which indicates good fitting of the experimental adsorption data of AY219 on the mixed oxide $\left(r^{2}=0.920\right)$. The $b$ constant related to the free energy of adsorption was found to be $0.007 \mathrm{~L} / \mathrm{mg}$. For the Langmuir type adsorption process, the isotherm shape can be classified in terms of the dimensionless constant (separation factor) which is defined by Eq. 8 (Webber and Chakkravorti 1974; Bulut et al. 2008):

$R_{\mathrm{L}}=\frac{1}{\left(1+b C_{0}\right)}$,

where: $b(\mathrm{~L} / \mathrm{mg})$ is the Langmuir constant and $C_{0}(\mathrm{mg} / \mathrm{L})$ is the initial AY219 concentration.

The $R_{\mathrm{L}}$ values indicate the shape of adsorption as unfavorable $\left(R_{\mathrm{L}}>1\right)$, linear $\left(R_{\mathrm{L}}=1\right)$, favorable $\left(0<R_{\mathrm{L}}<1\right)$, or irreversible $\left(R_{\mathrm{L}}=0\right)$. The $R_{\mathrm{L}}$ values calculated in the AY219-ST20 system were in the range $0.187-0.846$ (Fig. 2b) which proves favorable uptake of AY219 on ST20. The AY219 adsorption was more favorable at higher dye concentrations as the lower $R_{\mathrm{L}}$ values were calculated. The degree of favorability is connected with the irreversibility of the adsorption system, giving information about character of AY219-ST20 interactions. Increasing initial dye concentration, the $R_{\mathrm{L}}$ values tended toward zero (an ideal irreversible case) rather than unity (a completely reversible case).

Analyzing the adsorption data concerning applicability of nanosized silica-alumina mixed oxides for monoazo dye C.I. Acid Orange 7 , the obtained $Q_{0}$ value is high. It was reported that the monolayer adsorption capacities of two differing in composition silica-alumina oxide containing 3\% of $\mathrm{Al}_{2} \mathrm{O}_{3}$ and $97 \%$ of $\mathrm{SiO}_{2}$ as well as $96 \%$ of $\mathrm{Al}_{2} \mathrm{O}_{3}$ and $4 \%$ of $\mathrm{SiO}_{2}$ were equal to 5.56 and $41.4 \mathrm{mg} / \mathrm{g}$, respectively (Wawrzkiewicz et al. 2015, 2017b). Among a few mesoporous titanium-silica oxides synthesized by Rasalingam et al. (2013) for rodamine B adsorption, two adsorbents X-TiSi-03 $\left(\mathrm{TiO}_{2}: \mathrm{SiO}_{2}=1: 2\right)$ and X-TiSi-04 $\left(\mathrm{TiO}_{2}: \mathrm{SiO}_{2}=1: 3\right)$ were characterized by the highest adsorption capacities. The values under discussion calculated from the Langmuir adsorption model were found to be $41.2 \mathrm{mg} / \mathrm{g}$ for X-TiSi-03 and $44.1 \mathrm{mg} / \mathrm{g}$ for X-TiSi-04. It was stated that rhodamine B adsorption at $\mathrm{pH} 5-7$ on these materials occurs as a result of the electrostatic interactions between the surface hydroxyl groups $(-\mathrm{OH})$ of $\mathrm{TiO}_{2}-\mathrm{SiO}_{2}$ and the positively charged diethylamino groups of the dye. The presence of oxygen bridges Ti-O-Si also favors rhodamine B adsorption.

The Freundlich model assumed the multilayer coverage of adsorbate on the heterogenous surface of adsorbent and as well as no well-defined adsorption limit and distribution of adsorption heat. In the case of AY219 adsorption on ST20, an insignificantly higher value of the determination coefficient $\left(r^{2}=0.929\right)$ for the Freundlich isotherm model was found compared with the Langmuir $\left(r^{2}=0.920\right)$ and
Tempkin $\left(r^{2}=0.848\right)$ ones (Fig. 2$)$. The heterogeneity coefficient $(n)$ equal to 1.51 indicates the physical character of AY219 adsorption on the mixed silica-titanium oxide. The second constant $k_{\mathrm{F}}$ was found to be $6.15 \mathrm{mg} / \mathrm{g}$. This indicates the multilayer and complex nature of interactions of AY219 with the ST20 surface. Here adsorption of AY219 can occur not only by the electrostatic interactions between the protonated hydroxyl surface groups and AY219 anions but also hydrogen bonds and hydrophobic interactions including the $\pi-\pi$ interactions between the aromatic rings of the dye. Such types of interactions are in agreement with the previously proposed mechanisms of dyes adsorption on the surface of the mixed oxides (Ciesielczyk et al. 2017; Pal et al. 2016; Janoš 2003). The applicability of the Freundlich isotherm model for description of the acid (C.I. Acid Blue 29) and basic (C.I. Basic Blue 9) dyes adsorption on the $\mathrm{MgO}-\mathrm{SiO}_{2}$ oxide confirmed by the high values of determination coefficients can be found in Ciesielczyk et al. (2017) paper.

Taking into consideration the values of Tempkin constant $b_{\mathrm{T}}$ pertaining the sorption capacity with respect to sorption heat, it can be stated that the value of sorption heat increases (linearly) in the layer. The reason may be the interactions between the ST20 and the AY219 being in contact with it. As follows from the experimental data, this parameter reached the value $40.4 \mathrm{~J} / \mathrm{mol}$. The constant $A$ related to the maximum binding energy was calculated as $0.118 \mathrm{~L} / \mathrm{g}$. The low value of the determination coefficient $\left(r^{2}=0.848\right)$ suggests that the Tempkin model can not be used for description of equilibrium adsorption data of AY219 on ST20.

To investigate adsorption of AY219 on ST20 in detail, the kinetic studies were carried out the model system containing $20 \mathrm{~mL}$ of AY219 solution of the initial concentration $20 \mathrm{mg} / \mathrm{L}$ and $0.02 \mathrm{~g}$ of the adsorbent. The kinetic parameters were analyzed using the following models:

- the pseudo-first-order (PFO; Lagergren 1898)

$$
\log \left(q_{\mathrm{e}}-q_{t}\right)=\log \left(q_{\mathrm{e}}\right)-\frac{k}{2.303} t
$$

- the pseudo-second-order (PSO; Ho and McKay 1999)

$$
\frac{t}{q_{t}}=\frac{1}{k_{2} q_{\mathrm{e}}^{2}}+\frac{1}{q_{\mathrm{e}}} t
$$

- the intraparticle diffusion Weber-Morris (IPD)

$$
q_{t}=k_{\mathrm{id}} t^{0.5}+C_{\mathrm{i}}
$$

- Elovich

$$
q_{t}=\frac{1}{\beta} \ln (\alpha \beta)+\frac{1}{\beta} \ln (t)
$$

where: $q_{\mathrm{e}}$ and $q_{t}(\mathrm{mg} / \mathrm{g})$ are the amounts of AY219 adsorbed by ST20 at equilibrium and time t, respectively, $k_{1}(1 / \mathrm{min})$ is 
the rate constant of the pseudo-first-order kinetic model, $k_{2}$ $(\mathrm{g} / \mathrm{mg} \mathrm{min})$ is the rate constant of the pseudo-second-order kinetic model, $k_{\mathrm{i}}\left(\mathrm{mg} / \mathrm{g} \min ^{0.5}\right)$ is the intraparticle diffusion rate constant, $C_{\mathrm{i}}$ is the intercept, $\alpha(\mathrm{mg} / \mathrm{g} \min )$ is the initial adsorption rate, and $\beta(\mathrm{g} / \mathrm{mg})$ is the desorption constant related to the extent of surface coverage and chemisorption activation energy.

The above-mentioned parameters were calculated from the slopes and intercepts of the plots $\log \left(q_{\mathrm{e}}-q_{t}\right)$ versus $t$ (PFO), $t / q_{t}$ versus $t$ (PSO), $q_{t}$ versus $t^{0.5}$ (IPD) and $q_{t}$ versus $\ln (t)$ (Elovich).

Figure $3 \mathrm{a}$ presents the comparison of the four kinetic models and the experimental sorption data of AY219 adsorption on ST20 as a function of time. The dynamic equilibrium in the solution containing $20 \mathrm{mg} / \mathrm{L}$ of the dye was achieved after $120 \mathrm{~min}$ of phase contact time. The amount of AY219 adsorbed by ST20 increased with the increasing phase contact time and reached the maximum value equal to $9.7 \mathrm{mg} / \mathrm{g}$. The parameters listed in Table 1 indicate that the pseudo-first-order model cannot be applied for description of adsorption data as the adsorption capacity calculated from the PFO model $\left(q_{\mathrm{e}}=2.51 \mathrm{mg} / \mathrm{g}\right)$ deviates significantly from the experimental value $(9.7 \mathrm{mg} / \mathrm{g})$. It was also confirmed by
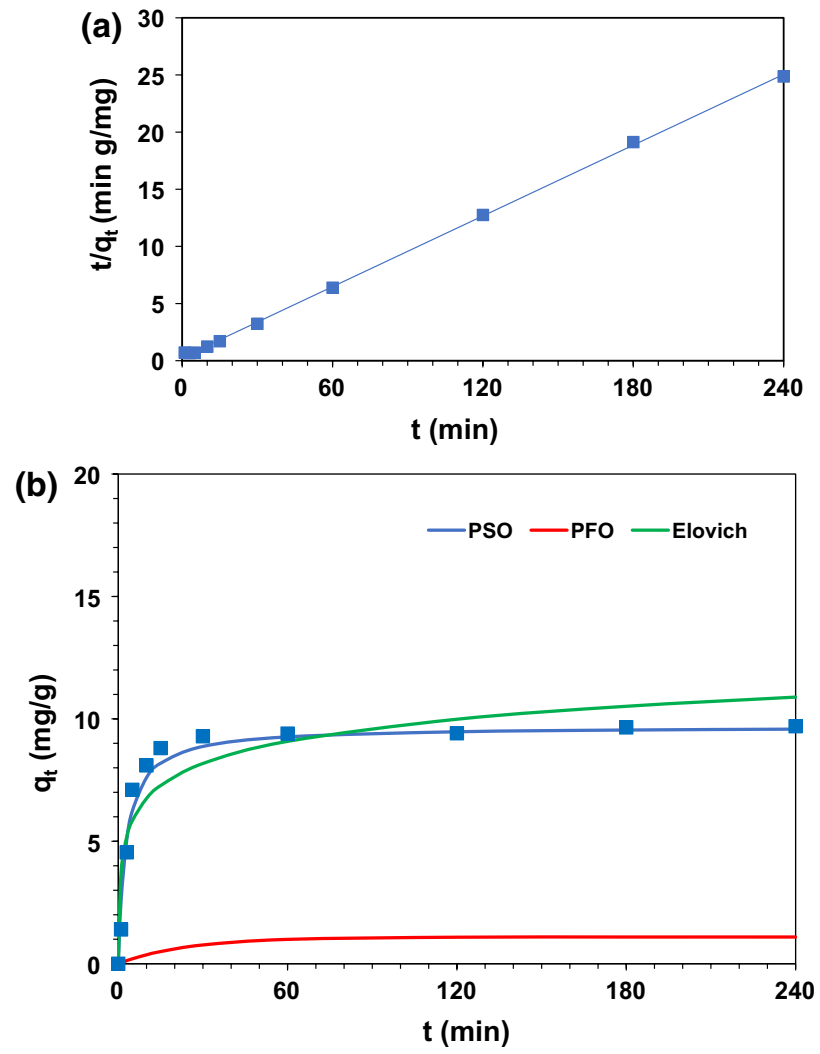

Fig. 3 Pseudo-second-order plot (a) and the fitting of the kinetic models to the experimental data (b) in the $20 \mathrm{mg} / \mathrm{L}$ AY219-ST20 system
Table 1 Kinetic parameters for adsorption of AY219 on ST20 using the pseudo-first-order, pseudo-second-order, Elovich, and intraparticle diffusion models

\begin{tabular}{llll}
\hline & Parameter & Unit & Value \\
\hline Kinetic model & $q_{\mathrm{e}, \text { exp }}$ & $\mathrm{mg} / \mathrm{g}$ & 9.7 \\
Pseudo-first-order & $q_{\mathrm{e}, \text { cal }}$ & $\mathrm{mg} / \mathrm{g}$ & 2.51 \\
& $k_{1}$ & $1 / \mathrm{min}$ & 0.016 \\
& $r^{2}$ & - & 0.681 \\
Pseudo-second-order & $q_{\mathrm{e}, \text { cal }}$ & $\mathrm{mg} / \mathrm{g}$ & 9.69 \\
& $k_{2}$ & $\mathrm{~g} / \mathrm{mg} \mathrm{min}$ & 0.0374 \\
& $r^{2}$ & - & 0.999 \\
Elovich & $\alpha$ & $\mathrm{mg} / \mathrm{g}$ min & 22.9 \\
& $\beta$ & $\mathrm{g} / \mathrm{mg}$ & 0.77 \\
Intraparticle diffusion & $k_{\mathrm{i}}$ & - & 0.767 \\
& $r^{2}$ & $\mathrm{mg} / \mathrm{g} \mathrm{min} \mathrm{min}^{0.5}$ & 1.64 \\
& & - & 0.766 \\
\hline
\end{tabular}

the low value of the determination coefficient $\left(r^{2}=0.681\right)$. The intraparticle diffusion rate constant calculated from the Weber-Morris model was $1.64 \mathrm{mg} / \mathrm{g} \min ^{0.5}\left(r^{2}=0.766\right)$. There can be distinguished two adsorption steps in the plot $q_{t}$ vs $t^{0.5}$, but the regression did not pass through the origin. It shows that the intraparticle diffusion is not the only one rate-limiting step in the AY219 sorption process on ST20 and the external mass transfer occurred simultaneously.

The experimental data were well described by the PSO kinetic model, which indicates that AY219 adsorption on ST20 takes place with the creation of strong chemical bonds. Based on the highest value of the determination coefficient $\left(r^{2}=0.999\right)$ for the plot $t / q_{t}$ versus $t$ (Fig. 3b) in the AY219-ST20 system, the adsorption capacity was found to be $9.69 \mathrm{mg} / \mathrm{g}$.

The constant $\beta$ obtained from the Elovich equation is related to chemisorption rate and was equal to $0.77 \mathrm{~g} / \mathrm{mg}$; however, a slightly lower value of $r^{2}$ was obtained for the plot $q_{t} \mathrm{vs} \ln (t)$. Tanzifi et al. (2018) investigating adsorption of Amido Black 10B dye on the pure polyaniline and the polyaniline $/ \mathrm{SiO}_{2}$ nanocomposite, Ciesielczyk et al. (2017) analyzing C.I. Acid Blue 29 removal using $\mathrm{MgO}-\mathrm{SiO}_{2}$ oxide, as well as Wawrzkiewicz et al. (2015, 2017b) studying the C.I. Acid Orange 7, C.I. Direct Blue 71 and C.I. Reactive Black 5 adsorption on the $\mathrm{SiO}_{2}-\mathrm{Al}_{2} \mathrm{O}_{3}$ oxides also confirmed applicability of the PSO model for description of dye adsorption kinetics on different oxides.

\section{Influence of additives on dye adsorption}

The textile baths and effluents are rich in different types of surfactants. It is very important to establish their influence on the amount of dye adsorbed by an adsorbent as these auxiliaries are able not only to increase the dye retention but also dramatically decrease the sorption. The effect of SDS, 


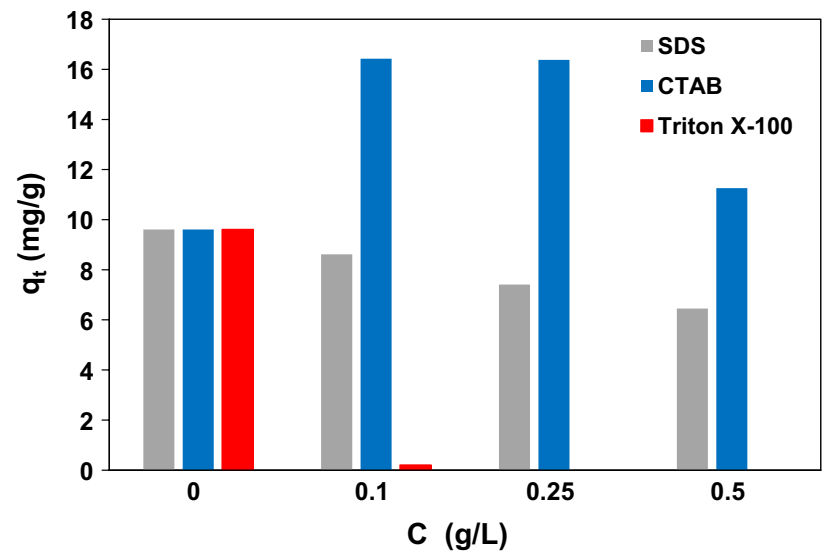

Fig. 4 AY219 adsorption by ST20 in the presence of the anionic, cationic, and non-ionic surfactants in the $20 \mathrm{mg} / \mathrm{L}$ AY219+0.1-0.5 g/L surfactant

$\mathrm{CTAB}$, and Triton $\mathrm{X}-100$ in the amounts ranging from 0.1 to $0.5 \mathrm{~g} / \mathrm{L}$ (below CMC of each surfactant) on the AY219 sorption from the solutions of the initial concentration $20 \mathrm{mg} / \mathrm{L}$ was investigated and is shown in Fig. 4.

As the concentration of the anionic surfactant SDS increased in the system, the AY219 retention by ST20 decreased as a result of competitive adsorption of SDS in comparison with dye anions $\left(\mathrm{AY}^{-}\right)$. Dramatic drop of the $q_{t}$ values with increasing Triton X-100 concentration was observed probably due to the strong hydrophobic interactions between $\mathrm{AY}^{-}$and non-ionic surfactant. Complexes of these types do not adsorb on ST20. The presence of CTAB in the system affects the increase in dye adsorption which is most likely caused by the strong interaction between the anionic form of AY219 and the cationic surfactant with the simultaneous hydrophobic interaction of such aggregate with the surface of ST20. The enhancement of dyes adsorption in the presence of different types of surface active agent has been thoroughly researched and described in the papers of (Janoš 2003; Janoš and Šmidová 2005).

\section{Electrokinetic characteristics of mixed oxide system in the presence of dye and surfactant}

In the aqueous solution surface, $\mathrm{TiOTi}, \mathrm{SiOSi}$, and TiOSi groups undergo hydroxylation; and the TiOTi-OH, $\mathrm{SiOSi}-\mathrm{OH}$, and TiOSi-OH groups with amphoteric character are formed. Depending on solution $\mathrm{pH}$ value, these groups can connect or disconnect proton which leads to positively and negatively charged groups formation (for example, $\mathrm{TiOTi}-\mathrm{OH}_{2}{ }^{+}$and $\mathrm{TiOTi}-\mathrm{O}^{-}$). The surface concentration of these charged groups decides about magnitude and sign of the total surface charge (Janusz 1994b). In the case of ST20 mixed oxide, the $\mathrm{pH}_{\mathrm{pzc}}$ assumes value, the 4.6,

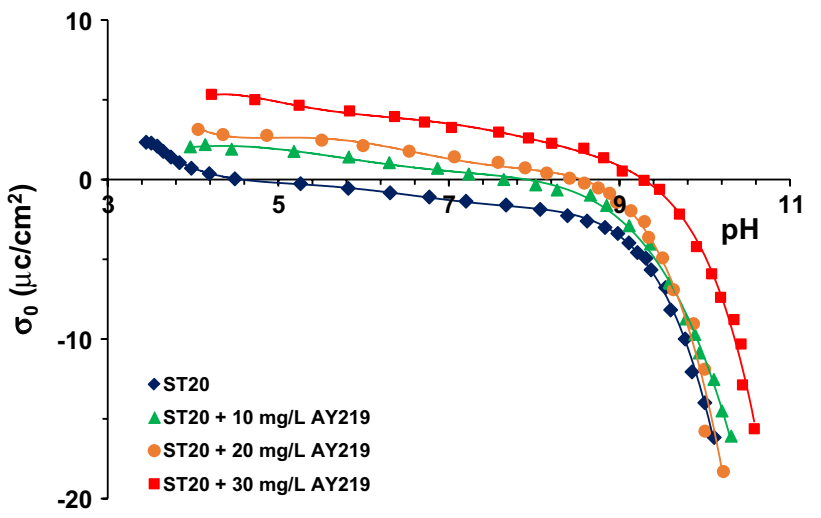

Fig. 5 Surface charge density of ST20 without and in the presence of AY219 with different concentrations

which indicates that at $\mathrm{pH}$ lower than 4.6 , the solid surface is positively charged; and at $\mathrm{pH}$ higher than 4.6 , it is negatively charged.

As can be seen in Fig. 5, the adsorption of anionic dye AY219 causes a considerable increase of the solid surface charge density in the whole range of studied $\mathrm{pH}$ and shift of the $\mathrm{pH}_{\mathrm{pzc}}$ point towards the higher $\mathrm{pH}$ values. Moreover, the higher the dye concentration is, these effects are more visible. At the dye concentration $10 \mathrm{mg} / \mathrm{L}$, the $\mathrm{pH}_{\mathrm{pzc}}$ assumes the value 8 , at $20 \mathrm{mg} / \mathrm{L}-8.5$ and at $30 \mathrm{mg} / \mathrm{L}-9.2$. Such behaviour is typically observed for simple anions, anionic dye molecules, anionic surfactants, and also anionic polymers (Skwarek et al. 2008; Wiśniewska et al. 2015, 2016a). Their adsorption on the solid surface causes creation of an additional number of positively charged surface groups, and as a result, the mixed oxide surface charge increases. The mechanism of this process can be summarized by the following reaction (e.g., with the participation of TiOTi-OH surface groups):

$\mathrm{TiOTi}-\mathrm{OH}+\mathrm{AY}^{-}+\mathrm{H}^{+} \leftrightarrow \mathrm{TiOTi}-\mathrm{OH}_{2}^{+} \mathrm{AY}^{-}$.

With the increasing dye concentration, the number of positive groups formed on the solid surface is greater; and as a consequence, the increase of $\sigma_{0}$ value is more pronounced in such a case.

The zeta potential results determined as a function of solution $\mathrm{pH}$ (Fig. 6) indicated that $\mathrm{pH}_{\text {iep }}$ of ST20 particles dispersed in the water medium is 3.2. The difference between $\mathrm{pH}_{\mathrm{pzc}}$ and $\mathrm{pH}_{\text {iep }}$ values obtained for ST20 aqueous suspension is 1.4. This can be caused by the fact that diffusion parts of electrical double layer (edl) formed inside pores overlap each other (Skwarek 2016). As a result, the composition of this part of edl changes which has influence on the electrokinetic parameters values. In addition, the systems containing anionic dye are characterized by the negative values of zeta potential in the whole range of studied $\mathrm{pH}$. This is probably

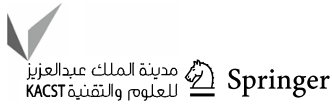




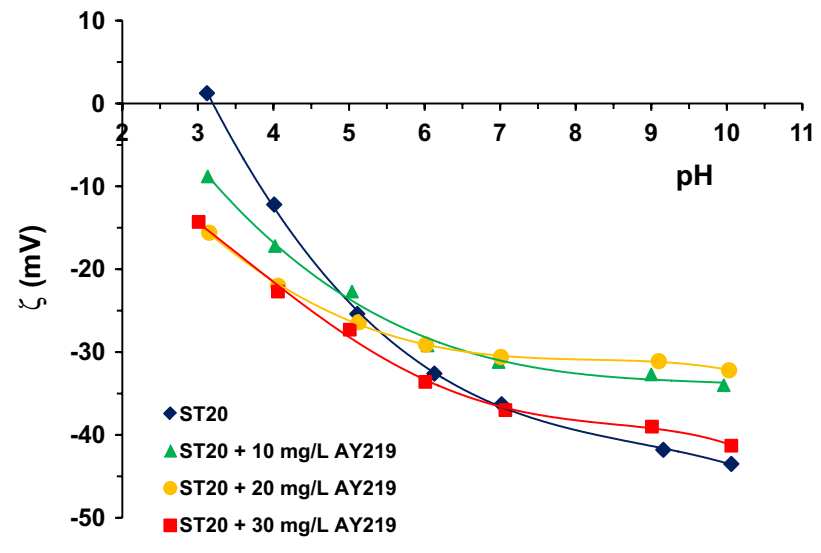

Fig. 6 Zeta potential of ST20 particles without and in the presence of AY219 with different concentrations

associated with the presence of negative charges of dye molecules in the area of slipping plane around the solid particle. These negative charges of the adsorbed dye coming from the second adsorbed dye layer are connected with the monolayer through hydrophobic parts of C.I. AY219 molecules. Some effects on the zeta potential changes may be due to shift of the slipping plane (Wiśniewska et al. 2016b; Ostolska et al. 2016) from the solid particle surface caused by the presence of adsorption bi-layer of dye molecules. The contributions of these two effects are reflected in the obtained final values of the electrokinetic potential of mixed oxide particles dispersed in the dye solution.

The ionic surfactant addition (both anionic SDS and cationic CTAB) influences the ST20 solid surface charge in the AY219 presence (Fig. 7). The non-ionic Triton $\mathrm{X}-100$ surfactant practically does not affect the $\sigma_{0}$ value of the solid surface. The adsorption of non-ionic surfactant (at the concentration $0.1 \mathrm{~g} / \mathrm{L}$ ) is minimal, because its molecules form strong complexes with the dye molecules in the

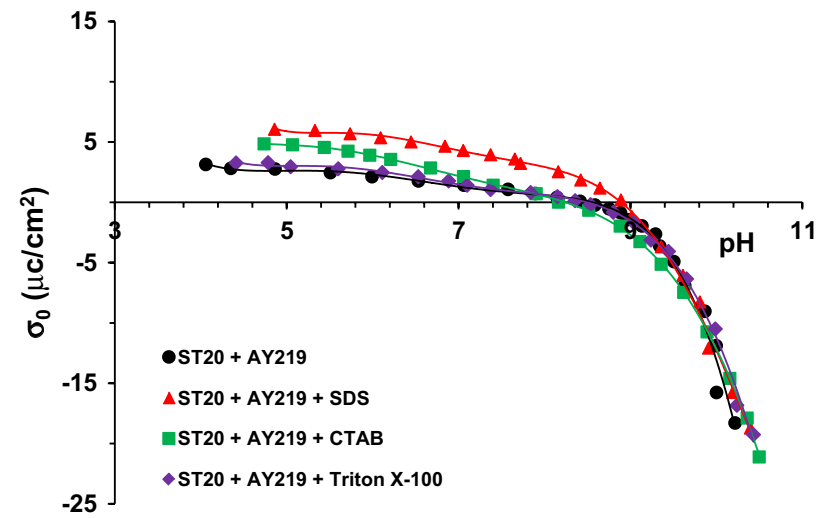

Fig. 7 Surface charge density of ST20 in the presence of AY219 with concentration $20 \mathrm{mg} / \mathrm{L}$ and various surfactants (with concentration $0.1 \mathrm{~g} / \mathrm{L})$ solution. Not very numerous uncomplexed dye molecules can adsorb on the solid surface creating a flat structure. When the available surface area is large, they can interact with the ST20 active sites through formation of hydrogen bonds with two nitrogen atoms present in the AY219 molecule (flat arrangement of dye molecules in the adsorption layer). Such mechanism of adsorption does not cause change in the solid surface charge density.

The considerable decrease of the solid surface charge density in the ST20-AY219 dye system in the presence of anionic SDS (Fig. 7) is confirmation of competitive adsorption of this surfactant (Wiśniewska et al. 2016c). The smaller molecules of SDS (in comparison to AY219 molecules) have easier access to the surface active sites of the adsorbent, and thus, they adsorb on the surface of the mixed oxide in a larger number (dye adsorption decrease in the SDS presence is observed). As a result, bonding of anionic surfactant causes creation of numerous positively charged surface groups and increase of surface charge density. In addition, the zeta potential of solid particles covered with the mixed dye-SDS layer assumes lower values than in the case of the suspension without the anionic surfactant (Fig. 8). The presence of numerous SDS molecules in the formed adsorption bi-layer is responsible for such electrokinetic behaviour of examined system.

On the other hand, adsorption of dye-CTAB complexes on the silica-titania mixed oxide results in noticeable increase of the solid surface charge density and a significant increase of ST20 particles zeta potential (Figs. 7 and 8). These experimental data suggest that the interactions of hydrophobic parts of dye and cationic surfactant are privileged and the aggregates are formed and their positive charge is directed towards the solution causing the considerable increase in the electrokinetic potential. Such

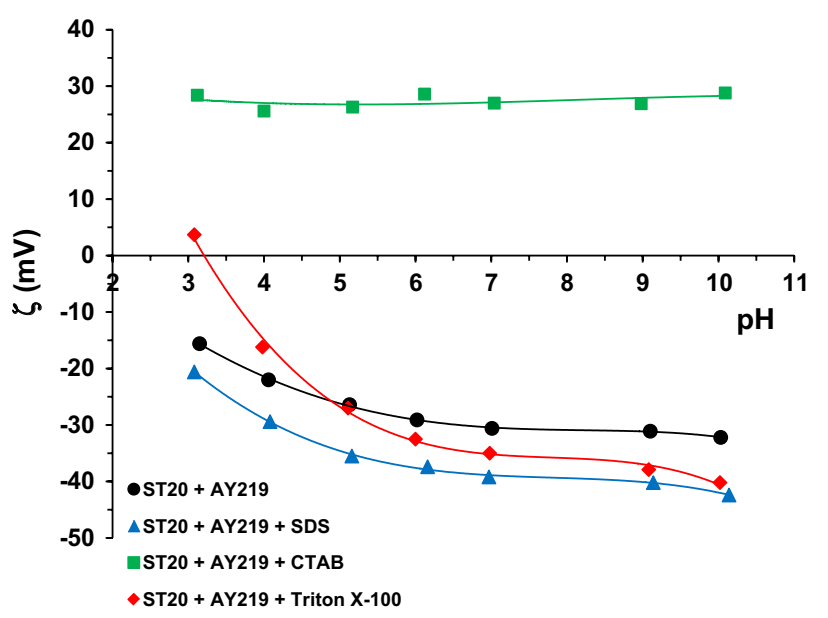

Fig. 8 Zeta potential of ST20 particles in the presence of AY219 with concentration $20 \mathrm{mg} / \mathrm{L}$ and various surfactants (with concentration $0.1 \mathrm{~g} / \mathrm{L})$ 
orientation of dye-cationic surfactant aggregates allows the adsorption of the second layer of these AY-CTAB complexes which is confirmed by the increase of AY219 adsorbed amount in the cationic surfactant presence.

\section{Conclusions}

The mixed silica-titanium oxide $\left(80 \% \mathrm{SiO}_{2}+20 \% \mathrm{TiO}_{2}\right)$ was applied as a potential adsorbent for the hazardous azo dye AY219 removal from aqueous systems. The adsorption capacity of the mixed oxide equals $338.4 \mathrm{mg} / \mathrm{g}$ for this dye. It is very high value in comparison to other examined mixed oxides, such as alumina-silica ones (for which adsorption capacity for acid dye was in the range $5.65-41.4 \mathrm{mg} / \mathrm{g}$ ). It proves that applied silica-titania oxide is efficient adsorbent for C.I. Acid Yellow 219 dye from wastewaters. The amount of AY219 adsorbed by ST20 was equal to $9.7 \mathrm{mg} / \mathrm{g}$ in the $20 \mathrm{mg} / \mathrm{L}$ AY2 19 system; the equilibrium time necessary was $120 \mathrm{~min}$. The kinetic data were well fitted using the pseudo-first-order model. Equilibrium studies using Freundlich, Langmuir, and Tempkin models revealed the complex nature of the dye adsorption on ST20.

The adsorption of anionic dye causes a significant increase of the solid surface charge density in the whole range of studied $\mathrm{pH}$ (creation of an additional number of positively charged surface groups on the ST20 surface) and decrease of zeta potential (the presence of negative charges of dye molecules in the area of slipping plane around the solid particle).

Significant changes in adsorption and electrokinetic properties of ST20-AY219 system were observed in the presence of such auxiliaries as SDS, CTAB, and Triton $\mathrm{X}-100$ surfactants.

The obtained results indicated competitive adsorption of SDS and dye molecules, both with anionic character. In the case of Triton X-100, the strong hydrophobic forces between $\mathrm{AY}^{-}$and non-ionic surfactant in the solution take place (complexes of these type have a weak tendency to adsorption on the solid surface). Strong interaction between the anionic form of AY219 and the cationic surfactant with the simultaneous possibility of bi-layer formation on the ST20 surface causes considerable increase of dye adsorption in the CTAB presence.

Acknowledgements The research leading to these results has received funding from the People Programme (Marie Curie Actions) of the European Union's Seventh Framework Programme FP7/2007-2013/ under REA Grant Agreement No. PIRSES-GA-2013-612484.

\section{Compliance with ethical standards}

Conflict of interest On behalf of all authors, I state that there is no conflict of interest.

Open Access This article is distributed under the terms of the Creative Commons Attribution 4.0 International License (http://creativeco mmons.org/licenses/by/4.0/), which permits unrestricted use, distribution, and reproduction in any medium, provided you give appropriate credit to the original author(s) and the source, provide a link to the Creative Commons license, and indicate if changes were made.

\section{References}

Bazan-Woźniak A, Nowicki P, Pietrzak R (2017) The influence of activation procedure on the physicochemical and sorption properties of activated carbons prepared from pistachio nutshells for removal of $\mathrm{NO}_{2} / \mathrm{H}_{2} \mathrm{~S}$ gases and dyes. J Clean Prod 152:211-222

Bazan-Woźniak A, Nowicki P, Pietrzak R (2018) Production of new activated bio-carbons by chemical activation of residue left after supercritical extraction of hops. Environ Res 161:456-463

Bulut E, Özacar M, Şengil İA (2008) Equilibrium and kinetic data and process design for adsorption of Congo Red onto bentonite. J Hazard Mater 154:613-622

Chung K-T (2016) Azo dyes and human health: a review. J Environ Sci Health C 34(4):233-261

Ciesielczyk F, Bartczak P, Zdarta J, Jesionowski T (2017) Active $\mathrm{MgO}-\mathrm{SiO} 2$ hybrid material for organic dye removal: a mechanism and interaction study of the adsorption of C.I. Acid Blue 29 and C.I. Basic Blue 9. J Environ Manag 204:123-135

Deryło-Marczewska A, Marczewski AW, Sz Winter, Sternik D (2010) Studies of adsorption equilibria and kinetics in the systems: aqueous solution of dyes-mesoporous carbons. Appl Surf Sci 256(17):5164-5170

Foo KY, Hameed BH (2010) Insights into the modelling of adsorption isotherm systems. Chem Eng J 156:2-10

Freundlich HMF (1906) Over the adsorption in solution. J Phys Chem 57:385-470

Garg VK, Kumar R, Gupta R (2004) Removal of malachite green dye from aqueous solution by adsorption using agro-industry waste: a case study of Prosopis cineraria. Dyes Pigment 62:1-10

Gorbik PP, Gun'ko VM, Zarko VI, Mischuk OA, Spivak OA, Chuiko AA (2007) Distribution of titanium oxide in nanocomposites of the system SiO2-TiO2. Rep Natl Acad Sci Ukr 1:143-148

Gun'ko VM, Nychiporuk YM, Zarko VI, Goncharuk EV, Mishchuk OA, Leboda R, Skubiszewska-Zięba J, Skwarek E, Janusz W, Yurchenko GR, Osovskii VD, Ptushinskii YG, Turov VV, Gorbik PP, Blitz JP, Gude K (2007a) Relationships between surface compositions and properties of surfaces of mixed fumed oxides. Appl Surf Sci 253:3215-3230

Gun'ko VM, Pakhlov EM, Skubiszewska- Zieba J, Blitz JP (2017) Infrared spectroscopy as a tool for textural and structural characterization of individual and complex fumed oxides. Vib Spectrosc 88:56-62

Gun'ko VM, Blitz JP, Gude K, Zarko VI, Goncharuk EV, Nychiporuk YM, Leboda R, Skubiszewska-Zieba J, Osovskii VD, Ptushinskii YG, Mishchuk OA, Pakhovchishin SV, Gorbik PP (2007b) Surface structure and properties of mixed fumed oxides. J Colloid Interface Sci 314:119-130 
Harshad L, Avinash K, Diby P, Sanjay G (2015) Biodegradation and detoxification of textile azo dyes by bacterial consortium under sequential microaerophilic/aerobic processes. EXCLI J $14: 158-174$

Hessel C, Allegre C, Maisseu M, Charbit F, Moulin P (2007) Guidelines and legislation for the dye house effluents. J Environ Manag 83:171-180

Ho YS, McKay G (1999) Pseudo-second order model for sorption processes. Process Biochem 34:451-465

Hunter RJ (1988) Zeta potential in colloid science: principles and applications. Academic Press, London

Janoš P (2003) Sorption of basic dyes onto iron humate. Environ Sci Technol 37:5792-5798

Janoš P, Šmidová V (2005) Effects of surfactants on the adsorptive removal of basic dyes from water using an organomineral sorbent-iron humate. J Colloid Interface Sci 291:19-27

Janusz W (1994) Electrical double layer at the metal oxide/electrolyte interface. In: Marcel Decker (ed) Interfacial forces and fields: theory and applications, New York

Janusz W (1994b) Electrical double layer in the system $\mathrm{TiO}_{2}$ (anathase)/ aqueous solution of $\mathrm{NaCl}$. Polish J Chem 68:1871-1880

Jin X-Ch, Liu G-Q, Xu Z-H, Tao W-J (2007) Decolorization of a dye industry effluent by Aspergillus fumigatus XC6. Appl Microbiol Biotechnol 74:239-243

Klepka T (2002) Effectiveness of forming of polymeric special sliding layers. Polymers 47:649-653

Klepka T, Dębski H, Rydarowski H (2009) Characteristics of highdensity polyethylene and its properties simulation with use of finite element method. Polymers 54:668-672

Lagergren S (1898) About the theory of so-called adsorption of soluble substances. Kungliga Svenska Vetensk Handl 24:1-39

Langmuir I (1918) The adsorption of gases on plane surfaces of glass, mica and platinum. J Am Chem Soc 40:1361-1403

Mielicki J (1991) Zarys chemicznej obróbki wyrobów włókienniczych. Wydawnictwo Naukowo-Techniczne, Warszawa (in Polish)

Nowicki P, Kazmierczak-Razna J, Pietrzak R (2016) Physicochemical and adsorption properties of carbonaceous sorbents prepared by activation of tropical fruit skins with potassium carbonate. Mater Design 90:579-585

Ostolska I, Wiśniewska M, Nosal-Wiercińska A, Szabelska A, Gołębiowska B (2016) Adsorption layer structure in the system of the ionic block polyamino acid copolymers $/ \mathrm{SiO}_{2}$ particles. Colloids Surf A 488:138-144

Pal U, Sandoval A, Madrid SIU, Corro G, Sharma V, Mohanty P (2016) Mixed titanium, silicon, and aluminum oxide nanostructures as novel adsorbent for removal of rhodamine $6 \mathrm{G}$ and methylene blue as cationic dyes from aqueous solution. Chemosphere 163:142-152

Rasalingam S, Peng R, Koodali RT (2013) An investigation into the effect of porosities on the adsorption of rodamine B using titaniasilica mixed oxide xerogels. J Environ Manag 128:530-539

Robinson T, McMullan G, Marchant R, Nigam P (2001) Remediation of dyes in textile effluent: a critical review on current treatment technologies with a proposed alternative. Bioresour Technol $77: 247-255$

Skwarek E (2016) Application of silver tin research on hydroxyapatite. Advanced ceramic materials. WILEY-Scrivener Publishing LLC, USA

Skwarek E, Matysek-Nawrocka M, Janusz W, Zarko VI, Gun'ko VM (2008) Adsorption of heavy metal ions at the $\mathrm{Al}_{2} \mathrm{O}_{3}-\mathrm{SiO}_{2} / \mathrm{NaClO}_{4}$ electrolyte interface. Physicochem Probl Min Process 42:153-164

Tanzifi M, Yaraki MT, Kiadehi AD, Hosseini SH, Olazar M, Bharti AK, Agarwal S, Gupta VK, Kazemi A (2018) Adsorption of Amido Black 10B from aqueous solution using polyaniline/ $\mathrm{SiO}_{2}$ nanocomposite: experimental investigation and artificial neural network modeling. J Colloid Interface Sci 510:246-261

Tempkin MI, Pyzhev V (1940) Kinetics of ammonia synthesis on promoted iron catalyst. Acta Phys Chim USSR 12:327-356

Wawrzkiewicz M, Wiśniewska M, Gun'ko VM, Zarko VI (2015) Adsorptive removal of acid, reactive and direct dyes from aqueous solutions. Powder Tech 278:306-315

Wawrzkiewicz M, Hubicki Z, Polska-Adach E (2017a) Strongly basic anion exchanger Lewatit MonoPlus SR-7 for acid, reactive, and direct dyes removal from wastewaters. Sep Sci Tech. https://doi. org/10.1080/01496395.2017.1293098

Wawrzkiewicz M, Bartczak P, Jesionowski T (2017b) Enhanced removal of hazardous dye form aqueous solutions and real textile wastewater using bifunctional chitin/lignin biosorbent. Int J Biol Macromol 99:754-764

Wawrzkiewicz M, Wiśniewska M, Wołowicz A, Gun'ko VM, Zarko VI (2017c) Mixed silica-alumina oxide as sorbent for dyes and metal ions removal from aqueous solutions and wastewaters. Microporous Mesoporous Mater 250:128-147

Webber TW, Chakkravorti RK (1974) Pore and solid diffusion models for fixed-bed adsorbers. AIChE J 20:787-794

Weber WJ, Morris JC (1963) Kinetics of adsorption on carbon from solution. J Sanit Eng Div ASCE 18:31-42

Wiśniewska M, Chibowski S, Urban T (2015) Modification of the alumina surface properties by adsorbed anionic polyacrylamideimpact of polymer hydrolysis. J Ind Eng Chem 21:925-931

Wiśniewska M, Chibowski S, Urban T (2016a) Adsorption properties of the nanozirconia/anionic polyacrylamide system-effects of surfactant presence, solution $\mathrm{pH}$ and polymer carboxyl groups content. Appl Surf Sci 370:351-356

Wiśniewska M, Nowicki P, Bogatyrov VM, Nosal-Wiercińska A, Pietrzak R (2016b) Comparison of adsorption properties of $\mathrm{Mg}_{x} \mathrm{O}_{y}-$ $\mathrm{SiO}_{2}$ and $\mathrm{Zn}_{x} \mathrm{O}_{y}-\mathrm{SiO}_{2}$ in the mixed oxide-poly(vinyl alcohol) system. Colloids Surf A 492:12-18

Publisher's Note Springer Nature remains neutral with regard to jurisdictional claims in published maps and institutional affiliations. 